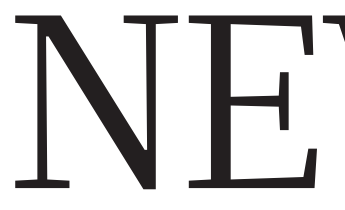

PHYsics How the huge volume of LHC data can be stored and saved for posterity $\mathbf{p . 4 4 7}$
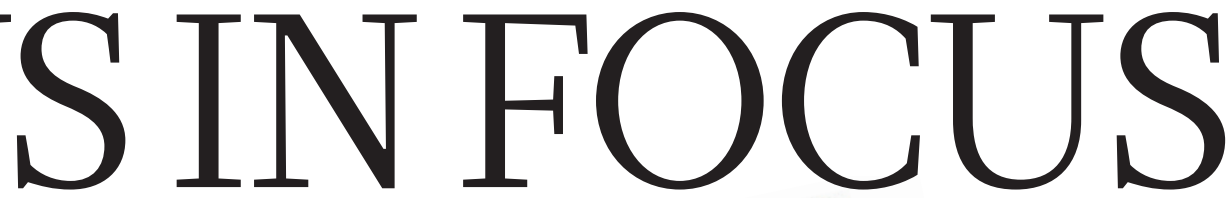

ECoLogy China is winning the fight to fend off damaging invasive species $\mathbf{p . 4 5 0}$
CONSERVATION IVOry seizures are up, but there's hope for the elephants $\mathbf{p . 4 5 2}$

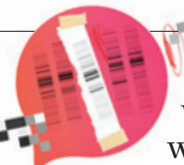

FRAUD Three scientists who chose to blow the whistle $\mathbf{p . 4 5 4}$

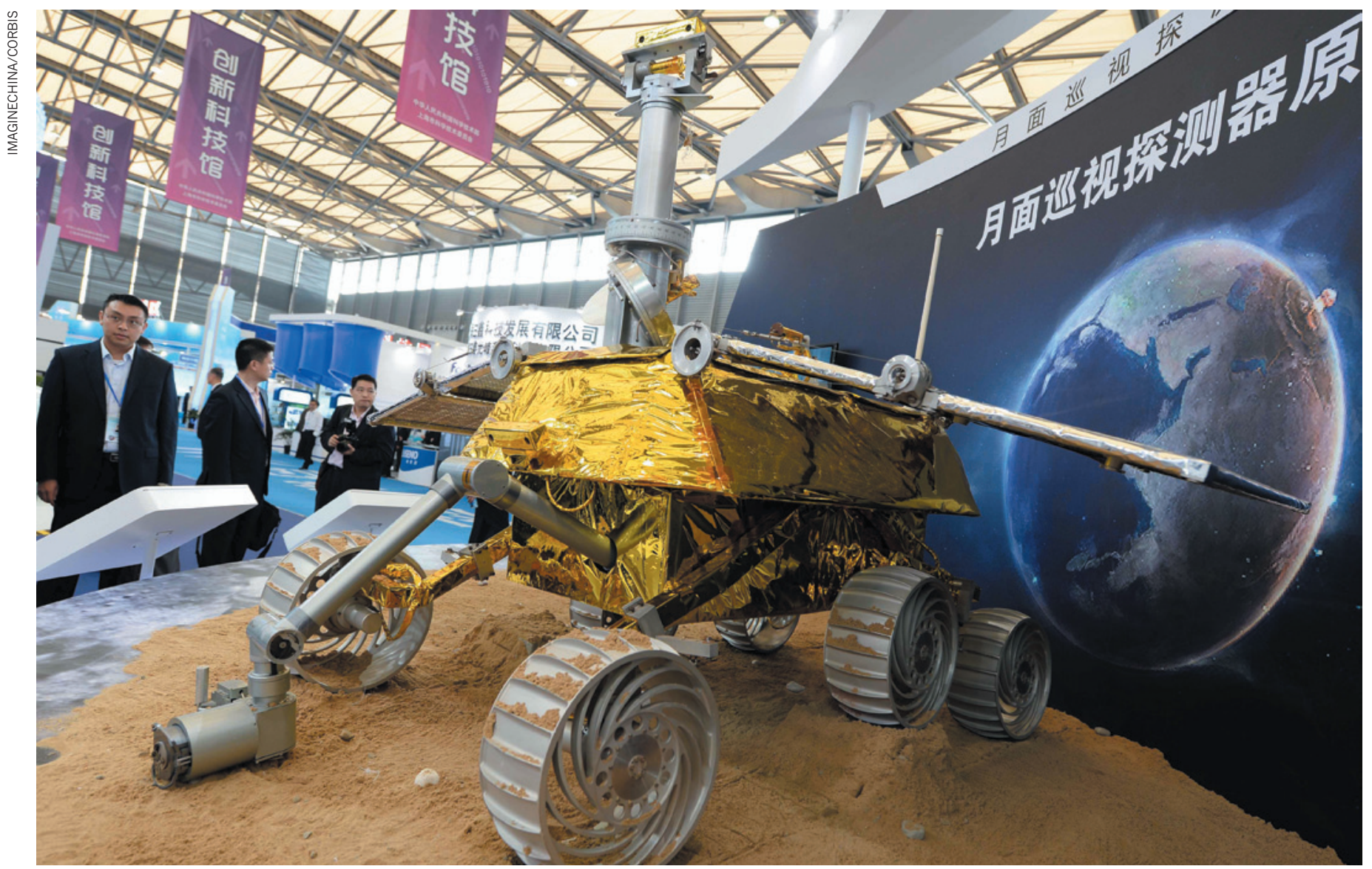

Preparing for lift-off: China displays a model of the Yutu rover that it plans to send to explore the Moon in December.

\title{
SPACE
}

\section{China aims for the Moon}

\section{Planned launch of lunar rover follows a string of triumphs for the country's space programme.}

\section{BY ALEXANDRA WITZE}

$\mathrm{N}$

ext month, a Chinese spacecraft called Chang'e-3 is scheduled to use braking plains of Sinus Iridum, broad swathe of lava flows on the near side of the Moon. The probe will then roll out a six-wheeled rover - the first machinery to explore the Moon's surface since 1976, when the Soviet Luna 24 mission scooped up a handful of soil and flew it back to Earth.

The landing would be the latest step in
China's methodical and almost flawless space programme. The country has achieved a string of triumphs in crewed space flight over the past decade, including putting humans into orbit and docking two craft in space. China lost its first and only Mars probe soon after launch in 2011, but both of its lunar orbiters flew successfully.

If Chang'e-3 lands safely on the Moon, China will join the Soviet Union and the United States as the only nations to have successfully landed exploratory spacecraft there. "You cannot call the Chinese a rising or emerging space power any more," says Bernard Foing, a lunar scientist at the European Space Agency in Noordwijk, the Netherlands. "They have shown they are very advanced.”

The roots of China's lunar programme trace back to the early 1990s, when money began to flow into work on crewed space flights and space scientists pushed for a parallel programme in lunar exploration. The result was a schedule of missions named after Chang'e, a luminescent Moon goddess. 
- Chang'e-1, an orbiter launched in 2007 by the Beijing-based China National Space Administration, mapped the entire Moon before it was deliberately crashed into the lunar surface in 2009. Change-2, launched in 2010, made higher-resolution maps before moving on to fly past the asteroid Toutatis, which it did last December.

Chang'e-3 is slated as the first step of China's second phase of exploration. The probe is expected to launch from the Xichang launch centre in Sichuan province in December.

If the mission launches on 1 December, Chang'e- 3 could enter into lunar orbit on 6 December, says Foing. The probe could then land in Sinus Iridum in the Moon's mid-latitudes on 16 December. Also known as the Bay of Rainbows, this location is close to where the Soviet Lunokhod-1 mission trundled in 1970-71, and on the opposite side of the great Mare Imbrium basin from where the US Apollo 15 mission landed (see 'Lunar leap').

“There's nothing particularly interesting about the spot, but it is a place we haven't been to before," says Paul Spudis, a Moon researcher at the Lunar and Planetary Institute in Houston, Texas. Sinus Iridum is also a fairly safe place to land, with flat plains and relatively few boulders.

If Chang'e-3 makes it to the surface, the lander portion will remain in one spot, kept warm during the frigid lunar nights by a radioactive heat source. It will survey Earth, the Milky Way and the rest of the sky with the first near-ultraviolet telescope ever deployed on the Moon, which will help astronomers to observe the birth and death of stars.

The solar-powered, 100-kilogram rover named Yutu, or 'jade rabbit' - is expected to explore the vicinity. Panoramic and other cameras will photograph the surroundings, and an a-particle X-ray spectrometer on a robotic arm will probe the soil's chemical composition. Ground-penetrating radar will also scan the Moon's subsurface to depths of 100 metres or more to study soil and rock structures, says Wenzhe Fa, a remote-sensing specialist at

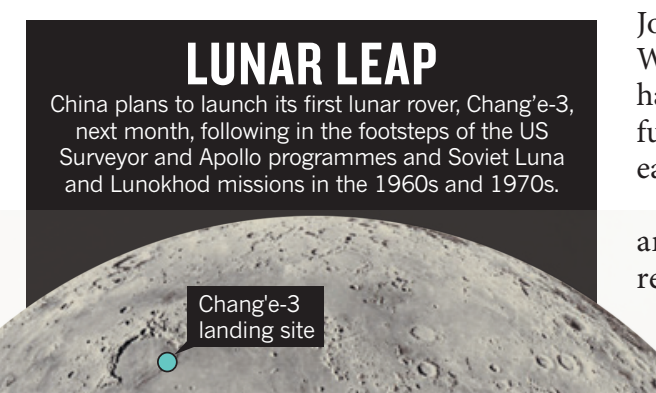

Johnson-Freese, an analyst at the US Naval War College in Newport, Rhode Island. "They have a long laid-out programme of very careful steps, but they are taking bigger steps with each flight," she says.

For the moment, those steps surpass what any other country is doing. South Korea recently announced that it would send an uncrewed lander to the Moon in 2020 (see Nature http://doi.org/p6h; 2013), but those plans - like others - remain just that, plans. Russia is considering the development of a series of orbiters and landers, and Japan has discussed a lander and rover, but schedules and budgets remain unclear. The United States has nothing lined up to follow its two current Moon orbiters, the Lunar Reconnaissance Orbiter and the Lunar Atmosphere and Dust Environment Explorer (LADEE) that is studying dust in the atmosphere.

In fact, LADEE faces a challenge when Chang'e- 3 arrives at the Moon. The Chinese orbiter is expected to release large amounts of exhaust gases when it enters lunar orbit, which LADEE will have to sort through to separate from naturally occurring dust. But NASA scientists cannot work on this task directly with those overseeing Chang'e-3 in Beijing because legislation pushed through by US Representative Frank Wolf (Republican, Virginia) forbids bilateral collaboration between the US agency and Chinese scientists.

However, others are moving forward with international agreements. The Paris-based European Space Agency will hold a meeting in February in Chengdu, China, to explore possible future joint missions involving the Chinese National Space Science Center in Beijing, which oversees the country's space-science research. The two have already collaborated on one satellite project: the Cluster/Double Star mission in 2003-07 to study Earth's magnetosphere. The National Space Science Center is also gearing up to launch China's first X-ray satellite in 2015, says its director, Wu Ji.

"They're running their own race," says Johnson-Freese. "They're not looking behind them."

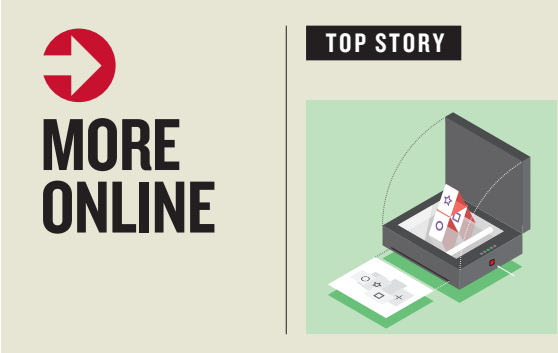

\section{Large} reproducibility study vets 13 psychology results go.nature.com/ hudts1

\section{MORE NEWS}

- Mice with just 2 Y-chromosome genes father babies go.nature.com/4qbrsi - Mexico begins construction of high-altitude $\mathrm{y}$-ray observatory go.nature.com/nneljr

- Crowdsourced maps help typhoon response go.nature.com/kmrmya

\section{NATURE PODCAST}

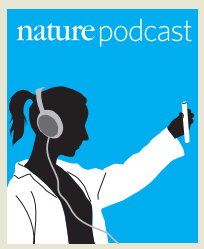

Happiness and the immune system; crystallizing proteins; and an LHC exhibition in London nature.com/ nature/podcast 